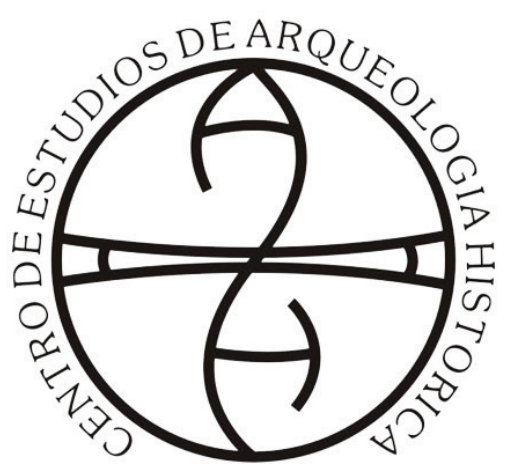

Centro de Estudios de Arqueología Histórica

Universidad Nacional de Rosario

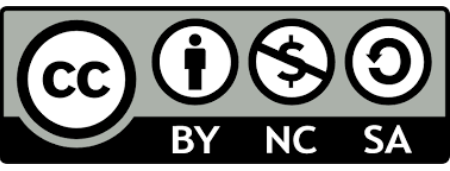

Teoría y Práctica de la Arqueología Histórica

Latinoamericana | Año X, Volumen 13 | 2021

Revista del Centro de Estudios de Arqueología Histórica, Facultad de Humanidades y Artes,

Universidad Nacional de Rosario

https://teoriaypracticaah.unr.edu.ar/index.php/index

https://rephip.unr.edu.ar/handle/2133/14804

ISSN en línea: 2591-2801

ISSN versión impresa: 2250-866X

Atribución-NoComercial-CompartirIgual 4.0 Internacional (CC BY-NC-SA 4.0)

https://creativecommons.org/licenses/by-nc-sa/4.0/deed.es

Fátima Solomita Banfi (ID: https://orcid.org/0000-00018879-3647). La población del cementerio de Carmen del Sauce entre 1900 y 1910 a través del libro de defunciones

\title{
La población del Cementerio de Carmen del Sauce entre 1900 Y 1910 A TRAVÉS DEL LIBRO DE DEFUNCIONES
}

\section{The Population of The Carmen del SAUCe CeMetery BetWeen 1900 AND 1910 THROUGH THE DEATH BOOK}

\author{
Fátima Solomita Banfi *
}

\section{Resumen}

Se presenta el estudio biodemográfico del cementerio histórico zonal de Carmen el Sauce durante la primera década del siglo XX. Se estudia el libro de defunciones que aporta informes completos sobre los óbitos, analizando los datos personales básicos, las edades y causas de muerte, poniendo atención a enfermedades epidémicas. Con una alta cantidad demográfica urbana y rural en esos tiempos, existe un elevado número de inhumaciones en el camposanto. En él yacen criollos e inmigrantes europeos y de países americanos.

Palabras clave: biodemografía; defunciones; cementerio; demografía; Carmen del Sauce.

\section{Abstract}

This work is the biodemographical study of the Carmen el Sauce's historical cemetery during the first decade of the 20th century. Studied the deaht book that provides complete reports on deads, analyzing basic personal data, ages and causes of death, putting attention to epidemic diseases. With a high urban

* Centro de Estudios de Arqueología Histórica (CEAH). Facultad de Humanidades y Artes, Universidad Nacional de Rosario. Argentina. fatima.solomita@gmail.com 
and rural demographic in those times, there is a high number of burials in the cemetery. In it lies creoles, european immigrants and the americans countries.

Keywords: biodemography; deaths cementery; demography; Carmen del Sauce.

\section{Introducción}

La localidad de Carmen del Sauce está ubicada a $40 \mathrm{~km}$ al suroeste de la ciudad de Rosario. Su historia se remonta al año 1803 en que se instala la Posta El Sauce, conocida previamente como Puesto de Medina, sobre el Arroyo del Sauce por el que pasaba el Camino Real. Esta posta nace a raíz de la destrucción de varias postas o fortines como consecuencia de una prolongada sequía en los arroyos (Mikielievich, 1978).

Por el Camino Real y los Caminos de Postas circulaban bienes y personas, pero también, con éstos últimos, enfermedades. Ejemplo de ello fue la expedición de Potosí rumbo a Rosario o Buenos Aires que transportó junto a un millón de pesos la fiebre tifoidea. Tuvo que detenerse el convoy para recibir ayuda en Cañada de la Cruz del Río Tercero para que los curas del lugar asistieran a los enfermos (Penna, 1917, pp. 8-19).

Para 1858, en el área cercana al Sauce se había instalado un puesto policial y un rancherío con una población rural dispersa de 534 habitantes según el censo de 1869.

La localidad llegó a ser el tercer núcleo poblacional del departamento Rosario con un importante centro económico-social hacia fines del siglo XIX; iniciada a partir de terrenos donados por dos familias: Corvalán y García.

Para 1887, según el censo de la provincia, contaba con un total de 1689 habitantes entre hacendados, agricultores, jornaleros y variadas profesiones. El casco urbano poseía escuela de varones y mujeres, capilla, diversos comercios, hoteles, tiendas y cafés, conservando su lugar como punto de paso de la mensajería de carros que cumplía el camino Rosario-Río Cuarto.

Respecto al sistema de salud, no figura que contara con dispensario pero sí con un médico, de los 34 existentes en la provincia, al mismo tiempo que un farmacéutico y 3 curanderos de los 12 censados. De esta manera podemos considerar un sistema sanitario de respuesta rápida ante emergencias o enfermedades menores.

En 1887, la epidemia de cólera estaba instalada en Rosario desde el año anterior y se dispararía un brote de viruela que duraría hasta 1890. Ya había pasado en 1871 una epidemia de fiebre amarilla. Sin embargo, en Carmen del Sauce lejos de decrecer, la población total llegó a triplicarse para el período 1858-1887.

Para el período 1900 a 1910, se calculó un crecimiento poblacional general (población urbana y rural) del 3\%, a partir de cálculos intercensales ${ }^{1}$ con los datos aportados por los censos nacionales de 1895 (2278 hab.) y 1914 (5538 hab.). Esta población estaba compuesta por criollos y un mínimo de inmigrantes.

Respecto al cementerio, el mismo está alejado unos $3 \mathrm{~km}$ del pueblo y es regional por haber sido Carmen del Sauce centro de distrito. No se especifica por qué el mismo está alejado del pueblo. Una de las causas puede ser las medidas higienistas impuestas por Carlos III de España en 1787, quien dispuso que los nuevos cementerios debieran mantener la distancia al centro poblado y cuya norma se extendió a todos los territorios de la Corona, incluyendo los virreinatos sudamericanos. Lo que se conoce es que no existen tumbas alrededor de la capilla pero sí una catacumba en su interior con los restos de la Sra. 
Patrocinia Corvalán de García, quien cedió las parcelas de tierra.

El camposanto del Sauce comenzó oficialmente sus entierros en 1877, según consta en una placa de mármol al ingreso del mismo, fecha en la que se establece como estructura delimitada espacialmente y construida por una comisión local extra eclesiástica. La comisión fue establecida a la par de la comisión de ampliación de la capilla, ambas conformadas por un presidente, vicepresidente, secretario, prosecretario, tesorero y vocales titulares y suplentes de "notables" del pueblo.

La lápida más antigua fechada registra la defunción en 1871; por lo tanto, los entierros poseen mayor antigüedad y por la importancia del mismo podría no haber sido trasladado sino haber sido un entierro en el predio (Solomita, 2019).

El cementerio cuenta en la actualidad con 1500 tumbas de diferentes tipos: nichos, panteones, perpetuas y tumbas en tierra con una ornamentación que comienza en el siglo XIX y llega hasta nuestros días. Los difuntos proceden de diferentes localidades: Carmen del Sauce, Acebal, Pavón Arriba, Coronel Domínguez, Uranga, Álvarez, Fuentes, Maizales, Piñeiro, Pavón, entre otras. Estas localidades fueron iniciadas por familias tenedoras de las tierras, algunas de las cuales, como Uranga, estableció su estancia en 1856 o la familia Saa Pereira con diferentes estancias a partir de ese mismo año y propietarios inmigrantes irlandeses de la década del '70 del siglo XIX, como los O'Connor.

El trabajo que se presenta aquí es el análisis de la composición de la población del cementerio histórico de Carmen el Sauce en la primera década del siglo XX, considerando las nacionalidades, las edades de muerte y las causas, poniendo atención a enfermedades epidémicas. Se obtuvieron los índices estadísticos básicos: tasa general de mortalidad (TGM), índice de salud y tasa de mortalidad proporcional por causa de muerte (TMP).

\section{Materiales y Métodos}

En la comuna se resguardan tres tomos de los libros de registro de defunciones (LRD) con los que se está trabajando y que comienzan en 1901-Tomo III- y llegan hasta nuestros días -Tomo V-. Los tomos anteriores están siendo tratados de localizar.

Los libros aportan informes completos sobre los óbitos, datos personales básicos: nombre, apellido, fecha de muerte (mes, día y hora), domicilio a nivel localidad, edad de muerte en días, meses y/o años, nacionalidad, profesión/trabajo, fecha de inhumación, causas de muerte, tipo y costo de la tumba.

Se fotografió el libro de defunciones, tomo III desde el folio número 1 hasta el número 50, pertenecientes a los años 1901 al 1911. El trabajo se continuará con la fotografía de los folios siguientes hasta al menos el año 1950. Se están tratando de localizar los tomos I y II que comienzan en el año 1877. Los datos contenidos en las fotografías fueron transcriptas a tablas excel para una mejor visualización y análisis más dinámico.

Del 1 de enero de 1901 y al 31 de diciembre de 1910 se totalizaron 1704 registros de inhumaciones. Las muertes en el período pueden ser mayores y no haberse realizado el registro al ser muertes no declaradas, por ejemplo, en casos de fetos abortados o muertes en el entorno rural o de estancias. Esta situación ya se consideraba en el Primer Censo General de 1869: "ha sido costumbre arraigada en las campañas enterrar los cadáveres sobre todos los párvulos, en pleno campo sin dar cuenta ni razón a las parroquias" (p.106). En el caso estudiado el cementerio siempre fue extra eclesiástico y el aviso debía darse, al por entonces, centro de distrito: Carmen del Sauce. Sin embargo, se revisó el libro de la iglesia donde se encuentran asentados bautismos pero algunas muertes. Sólo se encontraron nueve registros que indican fueron entierros en el cementerio y que no figuraban en LRD. Estos fueron ingresados a las tablas 
Excel. Cabe aclarar, que los asientos en el libro de la capilla pertenecen a apellidos reconocidos en el pueblo y sus tumbas fueron de fácil identificación en el cementerio.

Se efectuó el análisis estadístico poblacional general de los óbitos en el periodo señalado sobre las variables sexo, nacionalidad, causas de muerte y sobre grupo etario y causas de muerte.

\section{Metodología para el análisis de causas de muerte.}

Metodológicamente, para el análisis de las causas de defunción se establecieron grupos etarios para establecer el impacto de las mismas sobre las etapas de la vida en las que se dieron las muertes. Se establecieron grupos etarios siguiendo la clasificación del LRD respecto a los días de nacido hasta 30 $\mathrm{y}$ meses hasta los 12. El grupo etario de infantes comprende mayores de 1 año hasta los $10 \mathrm{y}$ el grupo siguiente, púberes de 11 a 15 años. El estadio 4, de 16 a 40 años se corresponde con el período fértil de la mujer de interés para las muertes por patologías relacionadas a los partos o post-partos. Los grupos etarios siguientes están establecidos cada 20 años.

Categorías etarias utilizadas:

\begin{tabular}{|l|l|}
\hline Código & Años \\
\hline 0 & $0-1$ mes \\
\hline 1 & $<1$ mes a 1 año \\
\hline 2 & $<1$ a 10 \\
\hline 3 & 11 a 15 \\
\hline 4 & 16 a 40 \\
\hline 5 & 41 a 60 \\
\hline 6 & 61 a 80 \\
\hline 7 & $>81$ \\
\hline
\end{tabular}

Para el análisis de las causas se siguió la clasificación de Rodríguez Pérez (1999) modificada por esta autora, siendo la definición específica para cada una de las enfermedades que componen las categorías las establecidas en el Manual MSD 2020 para profesionales. En la siguiente clasificación se transcriben las causas de muerte que figuran en LRD en cada categoría.

A) Respiratorias: bronquitis, bronconeumonía/neumonía/pulmonía, tos convulsa (tos ferina, coqueluche, crup) considerando que hay enfermedades virales y bacterianas en este grupo.

B) Gastrointestinales: enterocolitis, gastroenteritis, enteritis, gastritis, disentería.

C) Cardíacas: síncope cardíaco, miocarditis, insuficiencia valvular (mitral), ruptura de corazón, parálisis cardíaca.

D) Cerebro-vasculares: hemorragia cerebral (derrame), embolia, aneurisma, apoplejía fulminante, infarto cerebral.

E) Infecto-contagiosas (Epidémicas): Meningitis, Sarampión, Escarlatina, Tuberculosis, Tifoidea, Difteria, Viruela.

F) Infecciones: corresponden a aquellas relacionadas con las condiciones higienistas: tétano, septicemia, gangrena.

G) Accidentes: asfixia, sumersión, quemaduras, intoxicación, fracturas de cráneo, destrozado 
por el tren, contusiones.

H) Muertes violentas: herida/s por arma de fuego, herida/s de arma blanca.

I) Otras causas: corresponden a otras enfermedades que figuran en menor cantidad: por ejemplo, uremia, hernia estrangulada, insolación, cirrosis, alcoholismo, ulcera, cálculos vesicales, convulsiones, cáncer, senectud, nefritis, entre otras.

J) Ginecológicas post-partum: eclampsia materna, hemorragia puerperal, metrorragia.

K) De la Infancia: atrepsia, debilidad congénita, inanición.

L) Nonatos y neonatos óbitos: nacidos muertos/abortos y muertos al momento de nacer o en horas, falta de desarrollo, nacimientos prematuros. ${ }^{2}$

Dentro del conjunto "Otras Causas" (I) existen una cantidad de enfermedades de mínima aparición, muchas de ellas que pueden ser provocadas por estadios de sífilis, enfermedad que en solo tres casos es mencionada como causal de muerte. La sífilis avanzada puede provocar: otitis, periostitis, meningitis sifilítica (se especifica así en el registro), dermatitis sifilítica, adenopatías, hepatoadenomegalias. Al cabo de los 10 a 25 años de contraída la sífilis, puede provocar aneurisma o insuficiencia aórtica mientras que entre los 20 a 30 años del contagio, se desarrolla ataxia locomotora.

La sífilis congénita ha sido incluida en este ítem a través de las patologías que puede generar.

Las patologías cardíacas de aneurisma e insuficiencia aórtica se han considerado dentro de las enfermedades cardíacas.

El cálculo de los índices estadísticos básicos consistió en: la tasa general de mortalidad (TGM), el índice de salud y la tasa de mortalidad proporcional por causa de muerte (TMP). Al no contarse con datos específicos de la población como los nacidos vivos no pudo calcularse la tasa de mortalidad infantil ni la tasa de mortalidad por sexos.

\section{Resultados}

La población general del cementerio según el LRD en el período de 1901 a 1910 es de 1695 al que se sumaron 9 registros del libro de la iglesia distribuidos en los años 1901 (2), 1902 (3), 1906 (2) y 1907 (2), lo que totalizan 1704 entierros en el cementerio.

La lectura del registro entre 1901 y 1910 ha establecido una edad máxima de muerte de 105 años correspondiente a una mujer española fallecida en el año 1901, siguiéndole otra de 102 años, argentina, el mismo año de fallecimiento, ambas por enfermedades gastrointestinales. Respecto a la edad mínima registrada, es la de nonatos (fetos).

Respecto a la clasificación por sexos, el 50\% de los óbitos corresponden al sexo masculino mientras que el 39\% es de sexo femenino y un 11\% indeterminado registrados como "N.N." o bien con "N. seguido del apellido" que corresponden a fetos/ niño/as nacidos muertos/muertos al nacer o en una mínima medida a adultos no reconocidos y que no figura el sexo.

Del total, el $87 \%$ de los inhumados son de nacionalidad argentina y el 13\% extranjeros especialmente de países limítrofes y europeos de diferentes nacionalidades, en su mayoría italianos, austríacos y españoles (Figura 1). 


\section{Argentinos-Extranjeros}

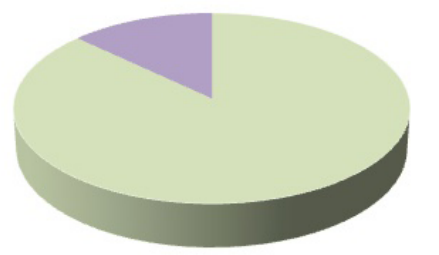

$$
\begin{aligned}
& \text { Argentinos } \\
& \text { Extranjeros }
\end{aligned}
$$

\begin{tabular}{|c|c|c|c|}
\hline Año & Frecuencia & $\begin{array}{c}\text { Porcentaje } \\
\text { Válido }^{1}\end{array}$ & $\begin{array}{r}\text { Porcentaje } \\
\text { Acumulado }\end{array}$ \\
\hline 1901 & 41 & 2,4 & \begin{tabular}{|l|}
2,4 \\
\end{tabular} \\
\hline 1902 & 166 & 9,8 & 12,2 \\
\hline 1903 & 142 & 8,4 & 20,6 \\
\hline 1904 & 133 & 7,8 & 28,4 \\
\hline 1905 & 181 & 10,6 & 39 \\
\hline 1906 & 218 & 12,8 & 51,8 \\
\hline 1907 & 234 & 13,8 & 65,6 \\
\hline 1908 & 173 & 10,1 & 75,7 \\
\hline 1909 & 202 & 11,9 & 87,6 \\
\hline \multirow[t]{2}{*}{1910} & 209 & 12,4 & 100 \\
\hline & 1704 & 100 & \\
\hline
\end{tabular}

Distribución de fallecidos anualmente
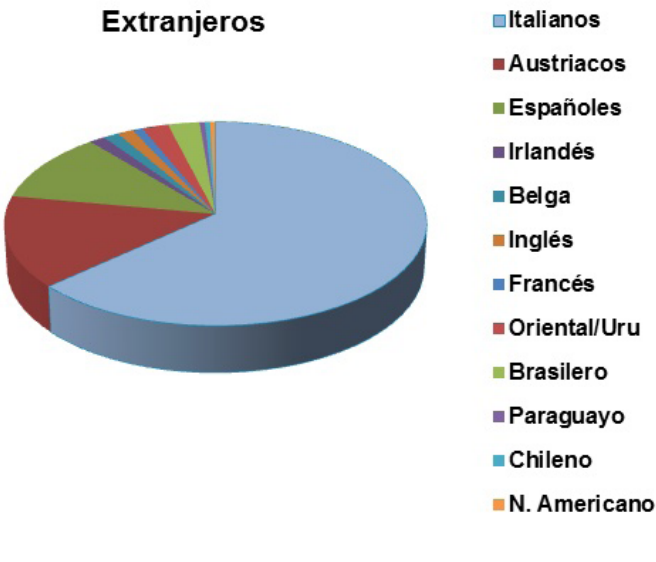

Figura 1. Composición de la población del cementerio entre 1901 y 1910 según nacionalidad.

Respecto a los extranjeros la población está compuesta por ciudadanos de: Italia, Austria, España, Irlanda, Bélgica, Inglaterra, Francia, Norteamérica, Uruguay, Brasil, Chile y Paraguay. La cantidad de italianos, austríacos y españoles es representativa, los brasileros y uruguayos están mínimamente representados, mientras que el resto suele estar visible por uno o dos individuos en el lapso de los diez años estudiados. Para el gráfico siguiente sólo se han tomado los porcentajes mayores a 0,5 y se han discriminado por sexo (Figura 2). 


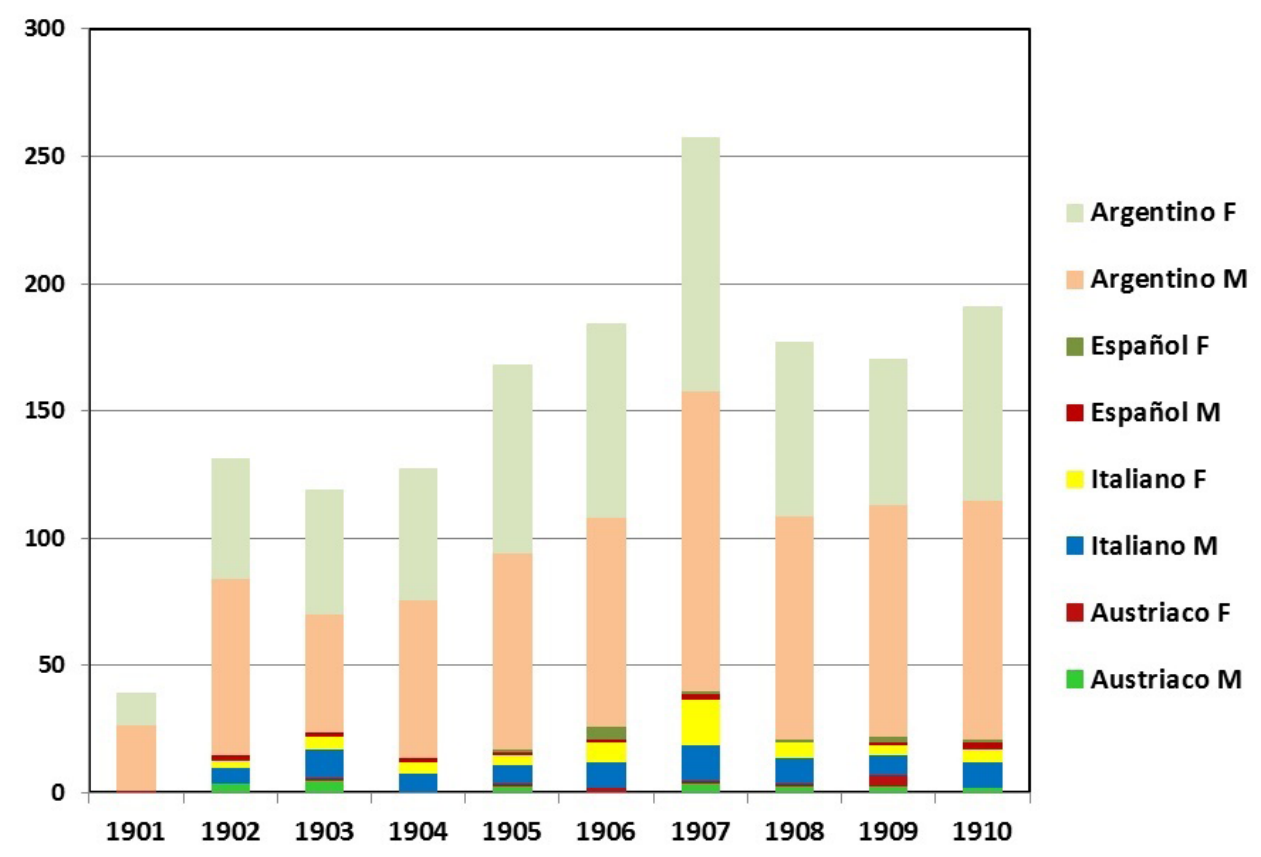

Figura 2. Distribución según sexo de extranjeros respecto a argentinos.

\section{Difuntos, edades y causas de muerte}

Para el periodo analizado la cantidad de óbitos visibiliza un incremento significativo a medida que se va adentrando la primera década del siglo XX pero tiende a amesetarse en 1909-1910; sin embargo desciende en 1911 un 3,8\% respecto del año anterior (1911=135 muertes según LRD).

La mortalidad media anual varía entre el 2,4\% y el 13,8\% en los diez años de análisis, siendo el año 1907 donde está el mayor porcentaje de fallecidos. Los años 1906 y 1910 también presentan un aumento en la mortalidad (Figura 3). La Tasa General de Mortalidad (TGM) para el período completo es del 32,3 por cada 1000 habitantes.

La mortalidad de los niños menores o iguales a un año de edad está representada por el 30,6\% (522) sobre el total de difuntos. Las causas atribuidas son las perinatales, falta de desarrollo, "debilidad congénita" (significado que no está claro a que alude el diagnóstico), atrepsia, enfermedades respiratorias y gastrointestinales.

Mientras que los mayores de 60 años están en el otro extremo con un bajo porcentaje de 6,8\% (116) sobre el total de los decesos. 


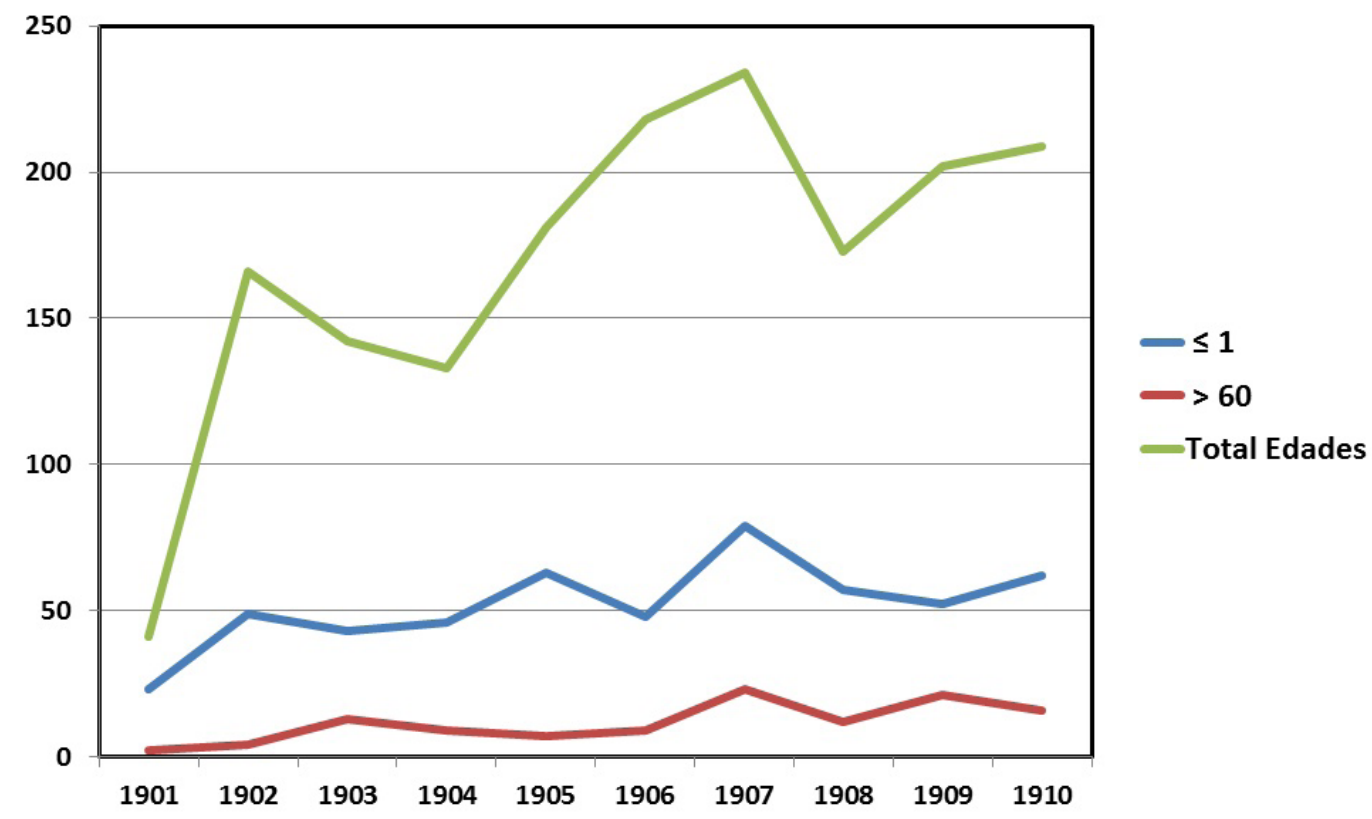

Figura 3. Distribución de la mortalidad general anual (TMG), de infantes menores a 1 año y mayores a 60 años.

La causa de la elevada mortalidad en 1907 se debe a patologías respiratorias (cat. A) que ocasionaron el 19,9\% y las epidemiológicas el 22,5\% de las muertes. Dentro de la categoría epidemiológicas (cat. E), la meningitis ocupa el 42,3\% y la tuberculosis el 30,8\%. Sobre el total de fallecimientos de ese año la meningitis y tuberculosis representan el $9,5 \%$ y el 7\% respectivamente.

Las enfermedades respiratorias infecciosas (Bronconeumonía,/Neumonía/Pulmonía) son ocasionadas por Streptococcus pneumoniae, bacteria que también ocasiona la meningitis bacteriana.

La meningitis a la que se hace referencia en el LRD correspondería a la meningitis bacteriana por ser la mayor causante de muertes. La meningitis viral se conocía antiguamente como meningitis aséptica y no hay registro de este nombre; sin embargo si aparece meningitis tuberculosa. La meningitis bacteriana puede ser provocada por: Neisseria meningitidis, Streptococcus pneumoniae, Haemophilus influenzae tipo B, Staphylococcus aureus. Para los grupos etarios de lactantes, niños y adultos jóvenes, las bacterias causantes más frecuentes son $N$. meningitidis y $S$. pneumoniae. La meningitis por $N$. meningitidis puede ocasionar la muerte en horas a partir de una infección rápida y grave denominada meningitis meningocócica, que produce coma y finalmente la muerte. Esta infección generalmente ocurre cuando ingresan patógenos al torrente sanguíneo a partir de una infección de vías aéreas superiores. La meningitis meningocócica es muy contagiosa entre personas que comparten espacios reducidos en condiciones de hacinamiento y pueden producir brotes epidémicos de meningitis.

$\mathrm{Su}$ transmisión se da persona a persona por microgotas de la respiración esparcidas en el aire de la persona enferma o portadora. 
La bacteria Haemophilus influenzae tipo B, por su parte, es la causante más frecuente de meningitis en niños de entre los 2 meses y 6 años de edad. Esta bacteria también se transmite con mayor frecuencia en lugares donde no existen adecuadas condiciones de vida (MSD 2020).

En el caso estudiado, para 1907, la mortalidad se dio en lactantes y niños menores de 4 años y en un único caso de adulto de 33 años.

La bacteria $H$. influenzae tipo B también es causante de la neumonía (MSD 2020).

Con el crecimiento de las neumonías se produce un aumento de decesos por tuberculosis. (Carbonetti, 2012).

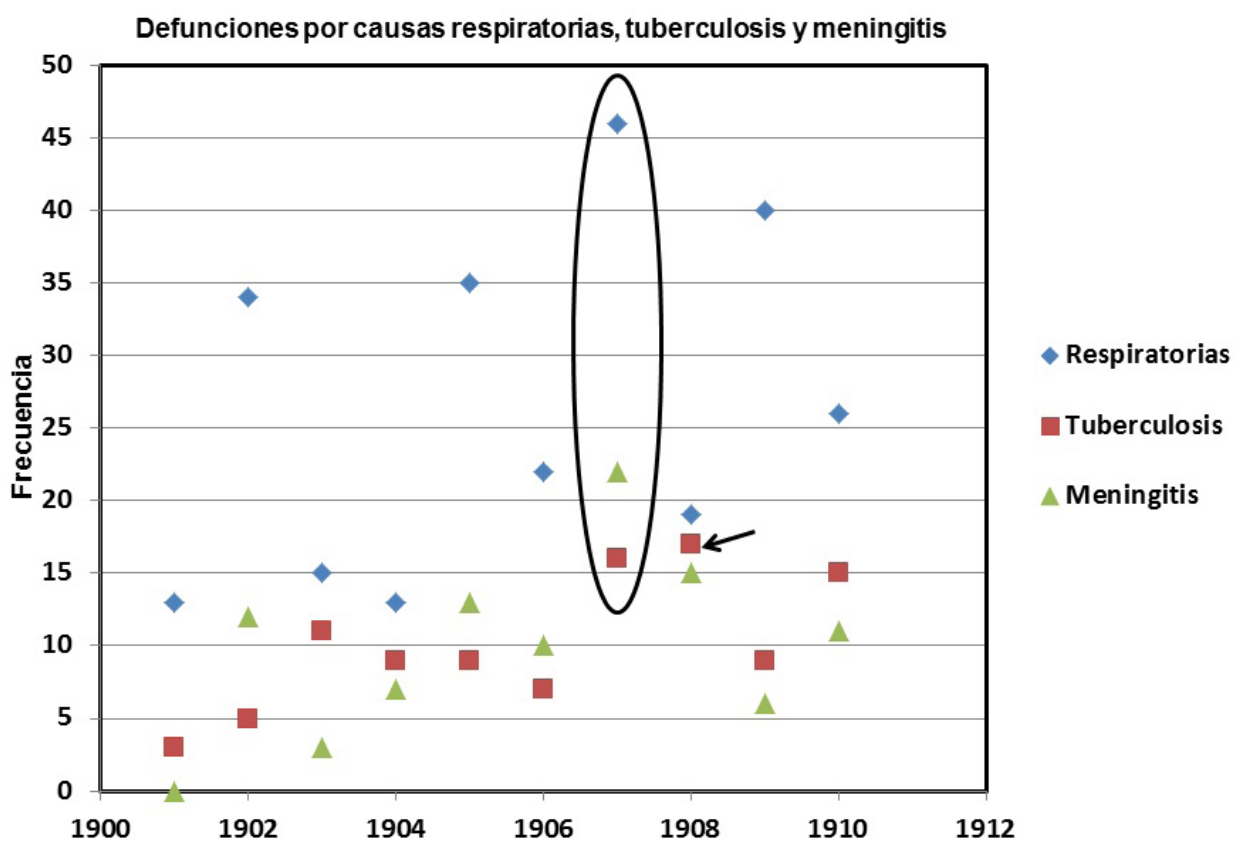

Figura 4. Defunciones por causas respiratorias en general, tuberculosis y meningitis (TMP).

En 1910, el porcentaje más elevado de muertes está dado por el grupo de enfermedades gastrointestinales (cat. B) que ocupan el 17,1 \% del total de ese año. La mayoría de las gastroenteritis son de origen infecciosas y se producen a través de la ingesta de alimentos o agua contaminada, o bien por transmisión de persona a persona. El agua contaminada a causa de la escasez de la misma pudo haber sido el disparador de esta enfermedad, agravándose durante todo 1910. 
Defunciones por enfermedades gastrointestinalesy respiratorias

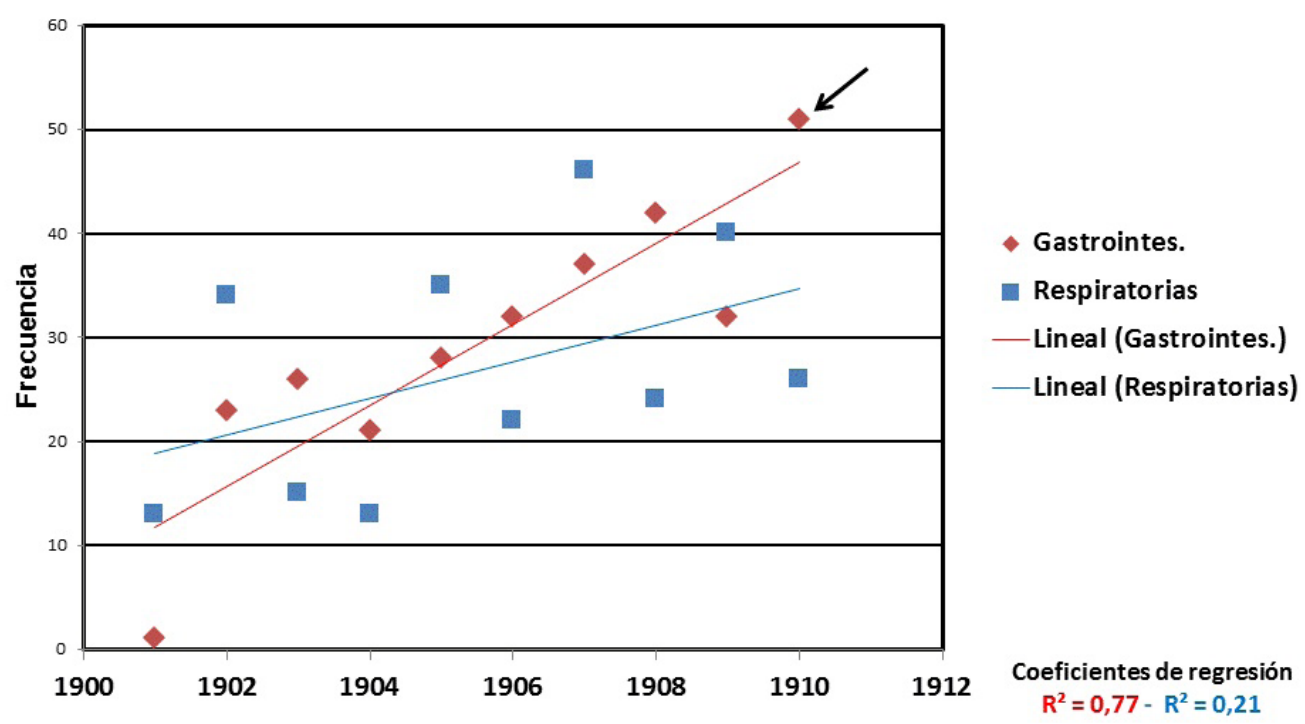

Figura 5. Defunciones por causas gastrointestinales y respiratorias (TMP).

Por registros climáticos, 1910 fue un año de sequía intensa para la pampa húmeda, especialmente para el sur de Santa Fe y centro-norte de Buenos Aires (Minetti, Vargas, Vega y Costa, 2007; Scarpati y Capriolo, 2013). La sequía fue más aguda en primavera pero ocurrió durante todas las estaciones del año, llegando las lluvias a bajar 300 a $600 \mathrm{~mm}$ anuales en tiempos que usualmente son de 600-1200 mm en la región (Minetti et al., 2007, p.30). Coincidentemente con este dato, la mayor cantidad de fallecimientos se produjo en los meses de enero a marzo y octubre a noviembre.

\section{Discusiones y conclusiones}

Entre los óbitos, una elevada frecuencia de nonatos e infantes hasta un año de edad se distribuye en los años estudiados. Las enfermedades más representativas de la mortalidad infantil son las perinatales, la debilidad congénita y la atrepsia.

Por el contrario, la mortalidad entre mayores de 60 años es menor de lo esperable y dentro de ella, las causantes por senectud tienen una frecuencia mínima $(0,7 \%)$ en comparación con variadas causas de muerte.

El intervalo de edad de mayores fallecimientos es el de menores de cinco años y luego vuelven a ascender entre los 16 y 40 años.

El índice de salud o índice Swaroop Vemura es de 11,56\% para el período estudiado; es un valor muy bajo debido a la mortalidad en edades infantiles y de edad reproductiva, si bien las muertes de mujeres en puerperio son escasas. 
La tasa de mortalidad general de 32,3 está sobre el promedio de la tasa de la Argentina para 1910 de 22,7 por mil habitantes (Grushka, 2014, p.94).

La mortalidad por sexos, si bien un porcentaje es indeterminado, indica que afecta mayormente a los hombres.

Respecto a las causas de muertes, Carbonetti (2012) nos indica que:

"la tuberculosis se transformó, en algunos momentos de la historia de la población argentina en una de las principales causas de muerte junto con las gastroenteritis en los niños, una vez que las grandes epidemias de cólera, viruela, fiebre tifoidea, tifus dejaron de incidir sobre la mortalidad" (Carbonetti, 2012, p.37).

Esto ha sido comprobado para la década estudiada, si bien se encontró también a la meningitis como una importante causa de decesos en algunos años.

De esta manera las enfermedades trasmisibles fueron la principal causa de muerte para el período estudiado. La falta de higiene, el hacinamiento en ranchos, aumento poblacional, el ambiente y las malas condiciones de vida son los factores causantes determinantes para la expansión de esta clase de enfermedades. Al ir terminando la década se nota un incremento de muertes por causas cardiológicas y cerebrovasculares. Estas causas de muerte se asocian a mejoras en políticas sanitarias y condiciones de vida. El análisis de décadas posteriores posibilitará conocer sobre la población del cementerio de Carmen del Sauce, inmigración, causas de mortalidad y su impacto en edades y sexos.

\section{Agradecimientos}

Este estudio integra el Proyecto de Investigación "Suelos Arqueológicos Históricos en el Área delimitada por las localidades de Alcorta, Villa Mugueta, Carmen del Sauce y la Vanguardia: edafología, historia y conservación patrimonial" acreditado ante la Universidad Nacional de Rosario y dirigido por esta autora. Se agradece a la presidenta comunal Grasiela Lucci y personal administrativo como así también a los vecinos de Carmen del Sauce.

\section{Notas}

1. Cálculo de población intercensal por Método de la Tasa de Variación: $P t==P o(1++r)^{1 / t}$, donde Pt es la población final, Po es la población inicial y $(1++r)^{1 / t}$, es el coeficiente de varianza en el intervalo de tiempo censal.

2. En el Libro de Defunciones se hace diferencia entre "nacido muerto" y "muerto al nacer", lo que hace suponer la supervivencia al parto en esta última categoría.

\section{Referencias bibliográficas}

Carbonetti, A. (2012) Historia epidemiológica de la tuberculosis en la Argentina. 1914-1947, Estudios $-N^{o}$ Especial, 37-52. Recuperado de https://www.researchgate.net/publication/277245481 [30 de octubre 2020] 
Gobierno de la Provincia de Santa Fe (1888). Primer Censo General de la Provincia de Santa Fe, Verificado 6, 7 y 8 de junio de 1887, bajo la dirección de Gabriel Carrasco, Director y Comisario del Censo, Buenos Aires, Imprenta Compañía Sudamericana de Billetes del Banco.

Gobierno Nacional (1872). Primer Censo General de la República Argentina. Verificado los días 15, 16 y 17 de septiembre de 1869 bajo la dirección de Diego G. de la Fuente, Superintendente del Censo. Buenos Aires: Imprenta del Porvenir.

Gobierno Nacional (1898). Segundo Censo General de la República Argentina. Verificado el día 10 de mayo de 1895 bajo la dirección de Diego G. de la Fuente, Superintendente del Censo, Buenos Aires, Talleres Gráficos de la Penitenciaría Nacional.

Gobierno Nacional (1916). Tercer Censo General de la República Argentina. Levantado el día 1 de junio de 1914 bajo la dirección de Alberto R. Martínez, Superintendente del Censo, Buenos Aires: Imprenta L. J. Rosso \& Cia.

Grushka, G. (2014). Casi un siglo y medio de mortalidad en la Argentina. Revista Latinoamericana de Población, 8 (15), 93-118.

Libro de Defunciones. Tomo III, Comuna de Carmen del Sauce, Santa Fe, Argentina

Merck Sharp y Dohme Corp (2020). Manual MSD para profesionales, Kenilworth, NJ., USA, Merck \& Co., Inc. Recuperado de https://www.msdmanuals.com/es-ar/professional [30 de septiembre de 2020].

Mikielievich, W. (1978). Orígenes de Carmen del Sauce-Evolución y decadencia del pueblo. Revista de Historia de Rosario, XVI (30), 128-132.

Minetti, J.L., Vargas W. M., Vega B. y Costa M. C. (2007). Las sequías en la pampa húmeda: impacto en la productividad del maíz. Revista Brasileira de Meteorologia, 22 (2), 218-232, doi:10.1590/ S0102-77862007000200007.

Penna. J. (1917). La historia de la medicina en Córdoba. Revista de la Universidad Nacional de Córdoba, 4(8), 3-43.

Rodríguez Pérez, E. (1999). La población de Ciudad Rodrigo durante el periodo 1871-1970. Recuperado de http://www.ciudadrodrigo.net/poblacion/poblacion.htm [1 de octubre de 2020].

Scarpati, O. E y A. D. Capriolo (2013). Sequías e inundaciones en la provincia de Buenos Aires (Argentina) y su distribución espacio-temporal. Investigaciones Geográficas, Boletín del Instituto geográfico, UNAM, 82, 38-51.

Solomita Banfi, F. (2019). Arqueología de la muerte en el cementerio de Carmen del Sauce, Departamento Rosario, Santa Fe, Argentina. Libro de Resúmenes del XX Congreso Nacional de Arqueología, Universidad Nacional de Córdoba, 1008-1009.

Recibido: 19 de febrero de 2021

Aceptado: 5 de abril de 2021 